Article

\title{
Study of Toxicity Assessment of Heavy Metals from Steel Slag and Its Asphalt Mixture
}

\author{
Rui Hu, Jun Xie *, Shaopeng Wu, Chao Yang@ and Dong Yang
}

State Key Laboratory of Silicate Materials for Architectures, Wuhan University of Technology, Wuhan 430070, China; hurui0907@whut.edu.cn (R.H.); wusp@whut.edu.cn (S.W.); hbyangc@whut.edu.cn (C.Y.); yangdhha@whut.edu.cn (D.Y.)

* Correspondence: xiejun3970@whut.edu.cn; Tel.: +86-134-7621-1303

Received: 18 May 2020; Accepted: 15 June 2020; Published: 18 June 2020

\begin{abstract}
Steel slag has been used widely as an aggregate in road application, but it could pose a contamination risk for the environment due to considerable heavy metals (HMs). To explore the leaching behavior and contamination risk of HMs from steel slag and its asphalt mixture is of great significance. In this study, the physical-chemical features, batch leaching test and semi-dynamic test were conducted to determine the mobility capability and leaching characteristics of HMs. The results show that steel slag presents a low pollution risk in short-term leaching, whereas the cumulative release mass of $\mathrm{Cd}, \mathrm{Ni}$, As and $\mathrm{Pb}$ are more than or approach the limits, which indicates that steel slag exhibits environment impacts to a certain extent. Steel slag covered with asphalt binder results in As and $\mathrm{Cu}$ reduced by $3.64 \%$ and $4.83 \%$. Diffusion is the main controlling mechanism of HMs in asphalt mixture and the mobility capability of most HMs were classed as "low mobility" (LI > 8). Asphalt stripping off can aggravate the release potential of HMs from asphalt mixture, but the pollution risk remains controllable.
\end{abstract}

Keywords: steel slag; asphalt mixture; heavy metal contamination; the leaching behaviors

\section{Introduction}

Waste solids are usually believed useless materials produced from all human industrial, commercial, building and demolition activities [1]. In the past, there were certain main ways to deal with waste solid including incineration and landfill, which can give rise to serious environment pollution. Hence, high-value reuse of waste solid materials plays a critical role in sustainable development. Additionally, large amounts of mineral materials have been consumed rapidly in road projects and construction. Attributed to the above, significant attempts have been made to study the engineering properties of various waste solids as raw materials in the construction industry, which is beneficial to relieve dependence on virgin mineral and divert waste materials from landfills. For instance, E. Tugrul et al. [2] studied waste marble as an ingredient in concrete, and indicated that the concrete which consists of waste marble instead of the coarse/fine aggregate, cement, and mixture material in certain rates exhibited higher strength. A Woszuk et al. [3] used zeolite materials as replacement of the filler in the warm-mix asphalt technology as an asphalt foaming additive, and found clinoptilolite could partially replace the traditional lime filler, without a negative impact on the asphalt mastic properties. Additionally, steel slag, characterized by high basicity, rich geometric features and excellent mechanical properties [4], has been justified its feasibility to replace aggregate in road engineering [5,6]. E Masad et al. [7] noted that the steel slag has the stronger bonding strength with asphalt binder in comparison to natural aggregates. Moreover, the water damage resistance, as well as the stiffness and fatigue life of steel slag based asphalt mixture also improved due to the vesicular and pitted structure of steel slag [8-10]. 
Different from the conventional hot-mixed asphalt (HMA), an asphalt mixture with steel slag does not need to consume substantial fossil fuels and mineral aggregates during raw material extraction. However, high-toxicity elements accumulate in the materials such as $\mathrm{Pb}, \mathrm{Cd}$ and $\mathrm{As}$ [11-13], and could re-enter the surrounding environment though rainwater leaching, or dispersal by surface weathering under acidic conditions [14,15], which results in the deterioration of ecology, environment and biological diversity via the enrichment of heavy metals (HMs) in the food chain $[16,17]$, and can lead to a variety of diseases, such as gastrointestinal diseases or neurological disorders $[18,19]$. In fact, roadway construction projects are beneficial to encapsulate the waste solids into an asphaltic matrix, which can prevent $\mathrm{HMs}^{\prime}$ release into the environment and reduce direct human exposure risk by minimizing the opportunity for contact [20-22]. However, owing to moisture damage, asphalt aging and vehicles load, the adhesion of asphalt mixture decreases, leading to asphalt stripping off from aggregate the [23,24]; meanwhile, those damages also aggravate the exposure risk and increase the pollution potential of steel slag.

Leaching is described as a complex process because many factors may influence the release of specific constituents from waste over a period of time. These factors include HMs concentration, $\mathrm{pH}$, geochemical compositions, physical characteristics and contact time [25-27]. Studies have confirmed that the metals existing in exchangeable and acid-soluble form are regarded to be the easily available fractions, while the metals in reducible and oxidizable form are considered inert and can only leach out under extreme conditions [28,29]. Kierczak et al. [25] found that porous slag with increased reactive surface area releases more trace elements under surface weathering conditions. Ash et al. [26] stated that rainwater simulation solutions can leach more HMs from slag with time than deionized water, and slag heterogeneity and contact time are the prominent factors for the toxic metal release.

The contamination risk for water supplies from waste materials is typically assessed using leaching tests, which involve bringing tested materials into contact with an extractant under simulated acidic conditions in a laboratory. There are two main types of leaching test, namely the batch leaching test and the semidynamic leaching test. Due to the absence of information about the behavior of contaminants in the medium or long term, batch leaching tests used to assess the contamination risk and the short-term leachability of hazardous materials have been regarded as a conservative assessment of toxic elements' release [30]. In semidynamic leaching tests (monolithic leaching test), on the contrary, waste materials encapsulated with asphalt binder or cement as an impermeable monolith are subjected to a leaching test in which the leachant is renewed with respect to time [31]. The methods can provide essential information about the leaching behaviors and the dominant leaching mechanism by allowing for the measurement of the time dependent release of trace elements and the calculation of observed elemental diffusivity [32].

In order to predict the leaching capability and contamination risk of HMs from steel slag and its asphalt mixture, an evaluation of the physical-chemical features of steel slag, a batch leaching test and a monolithic leaching test were performed to assess the release concentration of HMs. The objectives of this study are: (1) To determine the contamination potential of steel slag and its asphalt mixture of each HMs; (2) to assess the encapsulation ability of asphalt binder for HMs from steel slag; and (3) to determine the controlling leaching mechanism and observed diffusivity of HMs from the asphalt mixture.

\section{Materials and Methods}

\subsection{Raw Materials}

In this study, basic oxygen furnace slag (BOFS) was used, which was produced in Inner Mongolia, China. Basalt and commercial mineral filler were chosen from a local engineering project. The SMA-13 type of asphalt mixture with BOFS (coarse aggregate) and basalt (fine aggregate), defined as stone mastic asphalt with maximum dimension of aggregates of $13 \mathrm{~mm}$, was designed by the Marshall method [33] and the optimum asphalt-aggregate ratio was determined to be $6.1 \%$, where SMA- 13 
gradation was shown in Figure 1. BOFS, basalt and mineral filler in the mixture account for $79 \%, 11 \%$ and $10 \%$, respectively, and basically properties of aggregate and asphalt binder are shown in Tables 1 and 2.

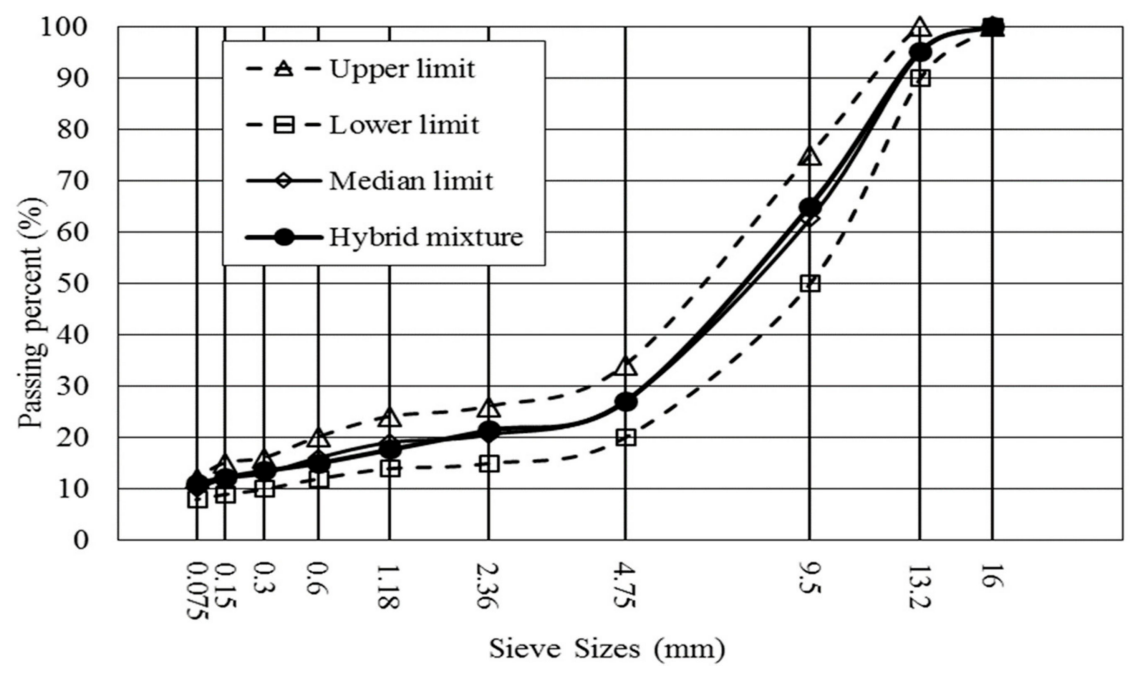

Figure 1. Hybrid gradation for asphalt mixture with basic oxygen furnace slag (BOFS) and basalt.

Table 1. Basic properties of BOFS and basalt.

\begin{tabular}{ccccc}
\hline \multirow{2}{*}{ Indexes } & Standard & \multicolumn{2}{c}{ Hybrid Mixture } & Requirements in \\
\cline { 3 - 4 } & & $\begin{array}{c}\text { BOFS (Coarse } \\
\text { Aggregate) }\end{array}$ & $\begin{array}{c}\text { Basalt (Fine } \\
\text { Aggregate) }\end{array}$ & $\begin{array}{c}\text { China } \\
\text { Apparent density }\end{array}$ \\
$\begin{array}{cccc}\left(\mathrm{g} / \mathrm{cm}^{3}\right) \\
\text { ASTM C127 }\end{array}$ & 3.66 & 2.75 & Min 2.6 \\
Crush value (\%) & ASTM C127 & 1.18 & 0.3 & Max 3 \\
Los Angeles abrasion (\%) & ASTM C127 & 12.9 & 17.1 & Max 22 \\
Free lime content (\%) & BS EN1744-1 & 8.3 & 16.8 & Max 22 \\
\hline
\end{tabular}

Table 2. Basic properties of asphalt binder (AH-70).

\begin{tabular}{cccc}
\hline Indexes & Standard & Measured Values & Requirements in China \\
\hline $\begin{array}{c}\text { Penetration at } 25{ }^{\circ} \mathrm{C}(0.1 \mathrm{~mm}) \\
\text { Softening point }\left({ }^{\circ} \mathrm{C}\right)\end{array}$ & AASHTO T228 & 63 & $60-80$ \\
Ductility at $15{ }^{\circ} \mathrm{C}(\mathrm{cm})$ & AASHTO T53 & 48 & Min 46 \\
rotational viscosity at $135{ }^{\circ} \mathrm{C}$ & AASHTO T201 & $>160$ & Min 100 \\
$($ Pa.s $)$ & AASHTO T48 & 0.596 & Max 3 \\
Flash point $\left({ }^{\circ} \mathrm{C}\right)$ & 413 & Min 260 \\
\hline
\end{tabular}

\subsection{The Physical-Chemical Features and Total Concentration of BOFS}

The physical-chemical features of BOFS are characterized by microscopic morphology and mineral constituents. The microscopic morphology of the samples was characterized with a scanning electron microscope (SEM) (JSM-5610LV; JEOL Ltd., Tokyo, Japan). Mineral constituents were analyzed by X-ray diffraction (XRD) measurements produced from Bruker (Karlsruhe, Germany) with non-monochromated $\mathrm{Cu} \mathrm{K} \alpha \mathrm{X}$-ray radiation.

Total concentration test: The total environmentally available concentration of elements in steel slag was assessed using the Environmental Protection Agency(EPA) method 3050b [34], partially modified. All samples of $0.2 \mathrm{~g}$ in powder form were placed in a bottle and mixed with $2 \mathrm{~mL}$ of $\mathrm{HNO} 3(65 \%$ purity), $6 \mathrm{~mL}$ of $\mathrm{HCl}$ (36\% purity) and $1 \mathrm{~mL}$ of $\mathrm{HF}(38.2 \%$ purity). The bottles were put in the special 
digestion device, in which the temperature rose to $180 \pm 10^{\circ} \mathrm{C}$. After $24 \mathrm{~h}$, the bottles were taken out from the digestion device and heated on a hot plate. Two milliliters of $\mathrm{HNO}_{3}(65 \%$ purity) were added to the bottle until thickened to ensure hydrofluoric acid exhausted. Finally, deionized water was added to the extracted solution to make $10 \mathrm{~mL}$ of the analysis solutions after filtering insoluble residue of the samples. The result is shown in Table 3.

Table 3. Initial Concentration of heavy metals (HMs) of BOFS, basalt and mineral filler.

\begin{tabular}{ccccccc}
\hline & \multicolumn{5}{c}{ Initial Concentration (mg/kg) } \\
\cline { 2 - 7 } Elements & \multicolumn{2}{c}{ BOFS } & \multicolumn{2}{c}{ Basalt } & \multicolumn{2}{c}{ Mineral Filler } \\
\cline { 2 - 7 } & Avg \pm Stdev & CV (\%) & Avg \pm Stdev & CV (\%) & Avg \pm Stdev & CV (\%) \\
\hline $\mathrm{Cd}$ & $89.65 \pm 4.12$ & 4.6 & $15.14 \pm 0.85$ & 5.6 & $11.34 \pm 0.15$ & 1.3 \\
$\mathrm{As}$ & $23.13 \pm 2.37$ & 10.3 & $\mathrm{ND}$ & - & $\mathrm{ND}$ & - \\
$\mathrm{Cu}$ & $70.38 \pm 2.84$ & 4.0 & $12.07 \pm 0.46$ & 3.8 & $12.65 \pm 0.67$ & 5.3 \\
$\mathrm{~Pb}$ & $978.41 \pm 13.47$ & 1.4 & $28.34 \pm 0.37$ & 1.3 & $22.56 \pm 1.34$ & 5.9 \\
$\mathrm{Cr}{ }^{6+}$ & $851.38 \pm 27.18$ & 3.2 & $16.85 \pm 1.37$ & 8.1 & $24.73 \pm 2.45$ & 9.9 \\
$\mathrm{Zn}$ & $141.05 \pm 14.33$ & 10.2 & $\mathrm{ND}$ & - & $8.38 \pm 0.67$ & 8.0 \\
$\mathrm{Ni}$ & $32.25 \pm 1.60$ & 5.0 & $2.5 \pm 0.12$ & 4.8 & $6.53 \pm 0.44$ & 6.7 \\
\hline
\end{tabular}

CV: The coefficient of variation (Stdev/Mean), \%; ND: Below detective content.

\subsection{Leaching Tests}

\subsubsection{Batch Leaching Test}

EPA method 1311, the toxicity characteristic leaching procedure (TCLP), is a test that simulates contamination releases that are likely to arise when a material is stacked in the exposed condition. The procedure involves analyzing leachate samples to determine if the material is hazardous. The TCLP is a batch leaching test conducted at a "liquid to solid $(\mathrm{L} / \mathrm{S})$ " ratio of 20:1 (L/kg) with sample size reduced to pass a $9.5 \mathrm{~mm}$ sieve prior to test. Two different leachate extraction fluids were selected according to the samples' alkalinity. Steel slag is a high-alkalinity waste solid, which is testified in the pre-experiment $\mathrm{pH}$ of $>5.0$. In this study, about $50 \mathrm{~g}$ of the samples were weighed into polypropylene bottles, and $1 \mathrm{~L}$ of the TCLP reagent $(0.1 \mathrm{M} \mathrm{HAc}, \mathrm{pH}=2.88 \pm 0.05)$ was added. Next, the bottles were tumbled in a rotary extractor at $30 \pm 2 \mathrm{rpm}$, and kept for $18 \pm 2 \mathrm{~h}$ at room environment.

In order to overcome the conservative characters of TCLP in the assessment of the ecotoxicity, a progressive TCLP test [32] was conducted on the tested samples. This is attributed to the long-term leaching behavior and the objective contamination risk for HMs at acid or base environment. The test ran for a total of five progressive cycles, in which each cycle was the same as the TCLP test. After each extraction, the residues from the filtering process were returned to the extraction bottles to repeat the extraction using a fresh portion of the extractant.

\subsubsection{Monolithic Leaching Test}

EPA method 1315 [34] was conducted on the asphalt mixture to study the long-term leachability and leaching mechanism of the samples in monolithic form. Method 1315 is a tank test where an intact sample is submerged in a vessel with the reagent, which consists of a blend of thick $\mathrm{H}_{2} \mathrm{SO}_{4}$ and $\mathrm{HNO}_{3}$ (weight ratio of $3: 1 ; \mathrm{pH}=4.5)$, and the reagent is renewed at set time intervals $(0.08,1,2,7,1428,42,49$ and 63 days), all method 1315 tests were conducted in triplicates. A liquid to exposed surface area ratio (L/SA) of $9 \pm 1 \mathrm{~mL}$ reagent per $\mathrm{cm}^{2}$ of pavement area was used throughout the method 1315 test. Considering asphalt stripping off from BOFS, we cut off the surface of asphalt mixture and exposed the BOFS aggregate, for which the preparation process of tested samples is presented in Figure 2. 


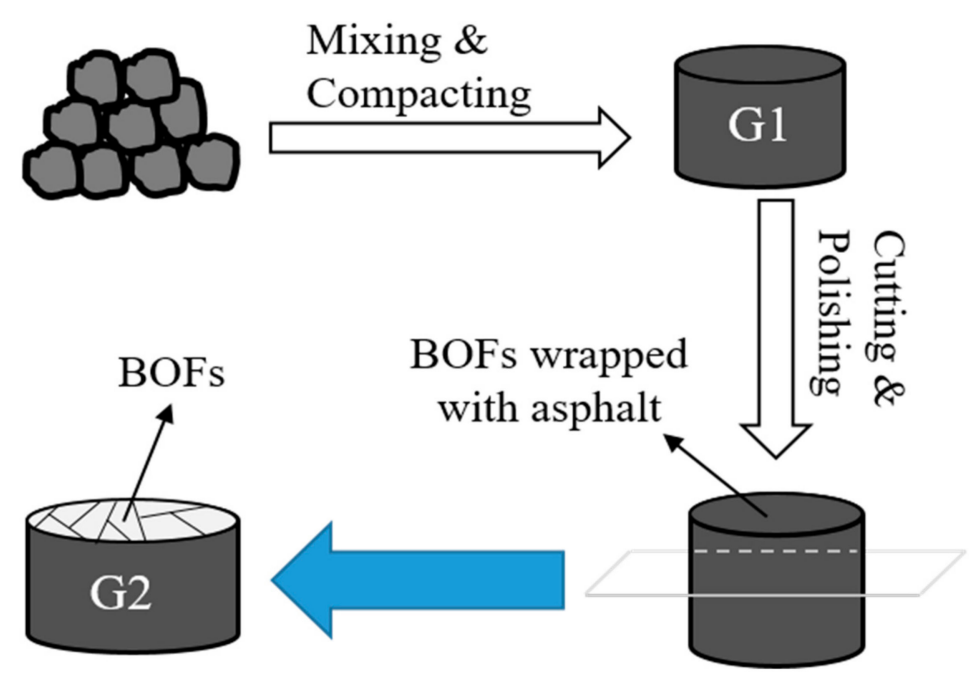

Figure 2. Preparation of the tested samples for the monolith test.

The equations for the cumulative mass release and observed diffusivity from the results of method 1315 can be calculated as follows in Equations (1) and (2). To calculate the observed elemental diffusivity for each interval $\left(D_{i}\right)$ from the monolithic samples, an analytical solution derived from Crank [35] for diffusion from a cylinder into an infinite batch was used.

$$
\begin{gathered}
D_{i}=\pi\left[\frac{M_{t i}}{2 \rho C_{0}\left(\sqrt{t_{i}}-\sqrt{t_{i-1}}\right)}\right]^{2} \\
D^{o b s}=\frac{1}{n} \sum_{i=1}^{n} D_{i}
\end{gathered}
$$

where: $D_{i}\left(\mathrm{~m}^{2} / \mathrm{s}\right)$ is mean observed diffusivity of a specific constituent for leaching interval; $M_{t i}\left(\mathrm{mg} / \mathrm{m}^{2}\right)$ is mass released per unit area of the specimen during leaching interval; $t_{i}(\mathrm{~s})$ is cumulative contact time after leaching interval; $\rho\left(\mathrm{kg} / \mathrm{m}^{3}\right)$ is the sample density; $C_{0}(\mathrm{mg} / \mathrm{kg})$ is initial leachable content and $D^{o b s}$ $\left(\mathrm{m}^{2} / \mathrm{s}\right)$ is mean observed diffusivity for the whole leaching test.

The leachability index (LI) is defined as the negative logarithm of the effective diffusion coefficient $D^{o b s}$, which is calculated by Equation (3). The leachability index is used for comparing the relative mobility of the different contamination. According to the Canada environmental criterion for the use and disposal of stabilized/solidified wastes, wastes with a leachability index of $<6.5$ are considered to have high mobility, $6.5<$ LI $<8.0$ moderate mobility, and LI $>8.0$ low mobility [20,36,37].

$$
\mathrm{LI}=-\log _{10}^{\left(D^{o b s}\right)}
$$

where: $D^{o b s}$ is expressed in units of $\mathrm{cm}^{2} / \mathrm{s}$.

\subsection{Chemical Analysis}

Chemical assessment of leachate is one test that is typically used to analyze the chemical toxicity of leachate samples. After the leachate samples are collected, they are typically filtered and the metals present in them are separated. The metals are typically quantified using an inductively coupled plasma atomic emission spectrometer (ICP-AES). The ecotoxicity and leaching risk of different heavy metals in BOFS are obtained in contrast to the environmental limits. In this chapter, the tested samples were made in triplicate to ensure the accuracy and that the content of heavy metals in the leachate was measured with average values. 


\section{Results and Discussions}

\subsection{Physical-Chemical Features and Total Concentration of Heavy Metals of BOFS}

Physical-Chemical Features

The SEM observation of BOFS is presented in Figure 3. Some pores with different sizes are distributed on the surface of BOFS, which agrees with the fact that BOFS is a porous material. Additionally, it was obvious that the morphology feature of the surface of BOFS is very rich, which is one reason to form the abundant microspores. According to Z Jin et al. [38], the rich porosity of the surface of the mineral slag can absorb much water, causing long-lasting leaching for mineral slag, which aggravates the pollution risk of BOFS.

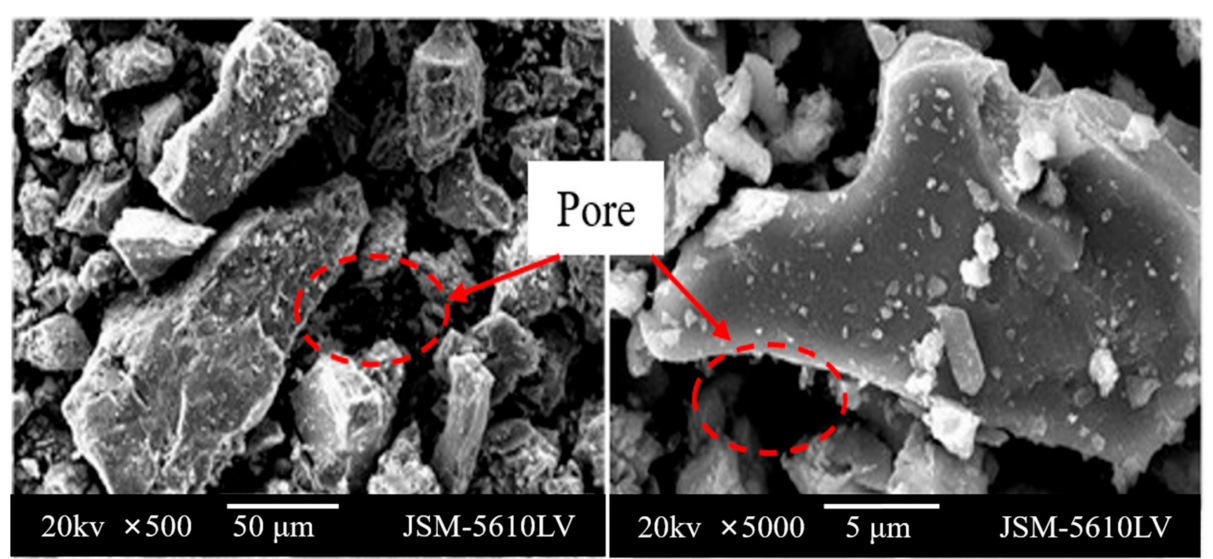

Figure 3. Scanning electron microscopy (SEM) images of BOFS.

X-ray diffraction provides clear clues for BOFS and the results showed that the dominant minerals were aluminosilicate $\left(\mathrm{CaO} \cdot\left(\mathrm{Al}_{2} \mathrm{O}_{3}\right)_{2} \cdot\left(\mathrm{SiO}_{2}\right)\right)$, silicate minerals $\left((\mathrm{CaO})_{x} \cdot\left(\mathrm{SiO}_{2}\right)\right.$ y), and FeO, as seen in Figure 4. Additionally, other complex compounds, including toxic metals such as hashemite $\left(\mathrm{BaCrO}_{4}\right)$ and crocoite $\left(\mathrm{PbCrO}_{4}\right)$ [39], in steel slag were not exhibited because they are beyond the limits of detection.

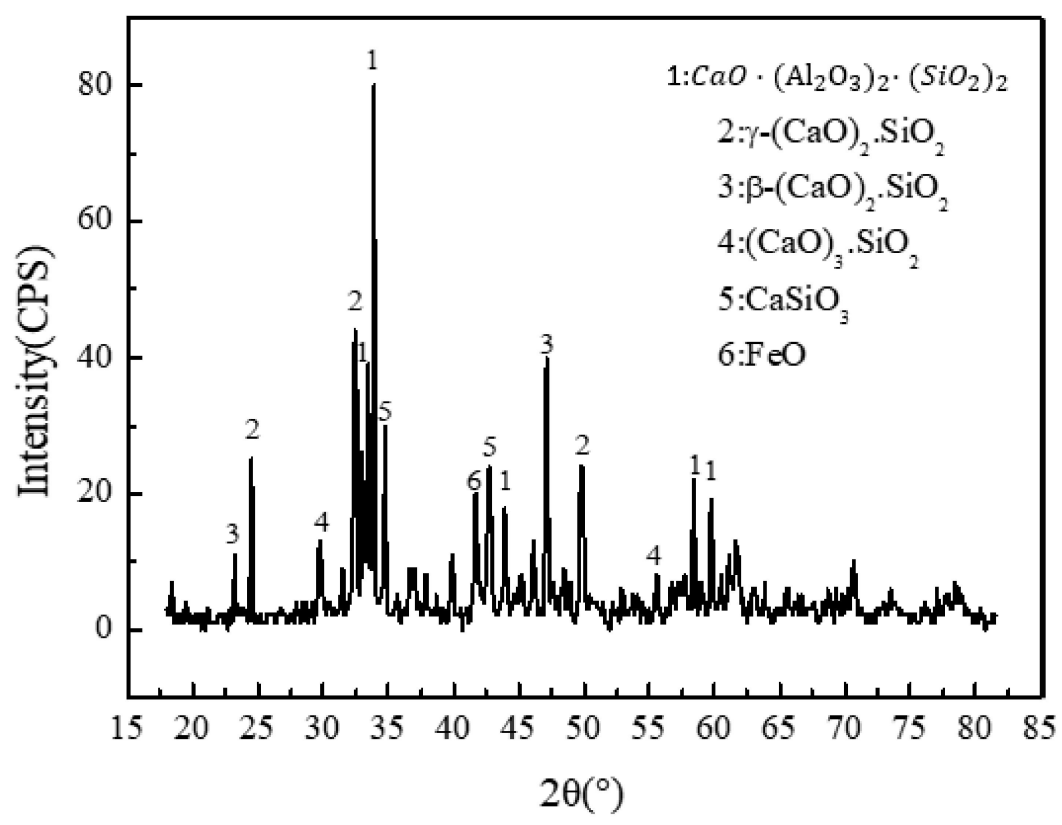

Figure 4. Mineral phases of BOFS. 
Table 3 shows the total concentrations of $\mathrm{Cd}, \mathrm{As}, \mathrm{Cu}, \mathrm{Pb}, \mathrm{Cr}^{6+}, \mathrm{Zn}$ and $\mathrm{Ni}$ in BOFS, basalt and mineral filler and the result presents that the content of heavy metals in basalt and mineral filler is far lower than in BOFS. According to the weight percentage of these materials, BOFS dominates. Additionally, due to the fine particle size of basalt and the mineral filler, the thicker asphalt membrane on the surface of the both materials could result in the lower heavy metal release. So, we regarded BOFS as the main source of heavy metal release from the mixture.

BOFS contains abundant toxic elements, defined as potential contamination of waste material. For the content of heavy metals, $\mathrm{Pb}$ and $\mathrm{Cr}^{6+}$ are considered high, followed by $\mathrm{Zn}, \mathrm{Cd}$ and $\mathrm{Cu}$, and $\mathrm{As}$ an $\mathrm{Ni}$ are deemed as low.

\subsection{Evaluation of the Leaching Toxicity of BOFS and its Asphalt Mixture}

\subsubsection{TCLP Test}

The batch leaching test allows the acidic extractant to erode and destroy the internal structure of BOFS, which causes HM release. In this experiment, the TCLP test was used to assess the contamination risk of HMs to aggregate and its asphalt mixture, and the results are summarized in Figure 5. The leaching concentration of HMs of BOFS with 0-3 mm range are higher than that with $3-5 \mathrm{~mm}$ range, but the values are in the same magnitude without large difference. This indicates that BOFS with small size, which is characterized by abundant pores and larger contact area, has greater capability for HM release. The leaching content of heavy metals in basalt is far lower to BOFS. Asphalt mixture presents a lower leaching content of HMs than BOFS, which shows that asphalt binder can mitigate HM release and that the asphalt mixture presents lower pollution risk. Additionally, measurements from the TCLP test are no more than the environmental limits. On the basis of the results, it is concluded that BOFS has no heavy metal contamination in short-term leaching and asphalt mixtures can be used for safe disposal for BOFS.

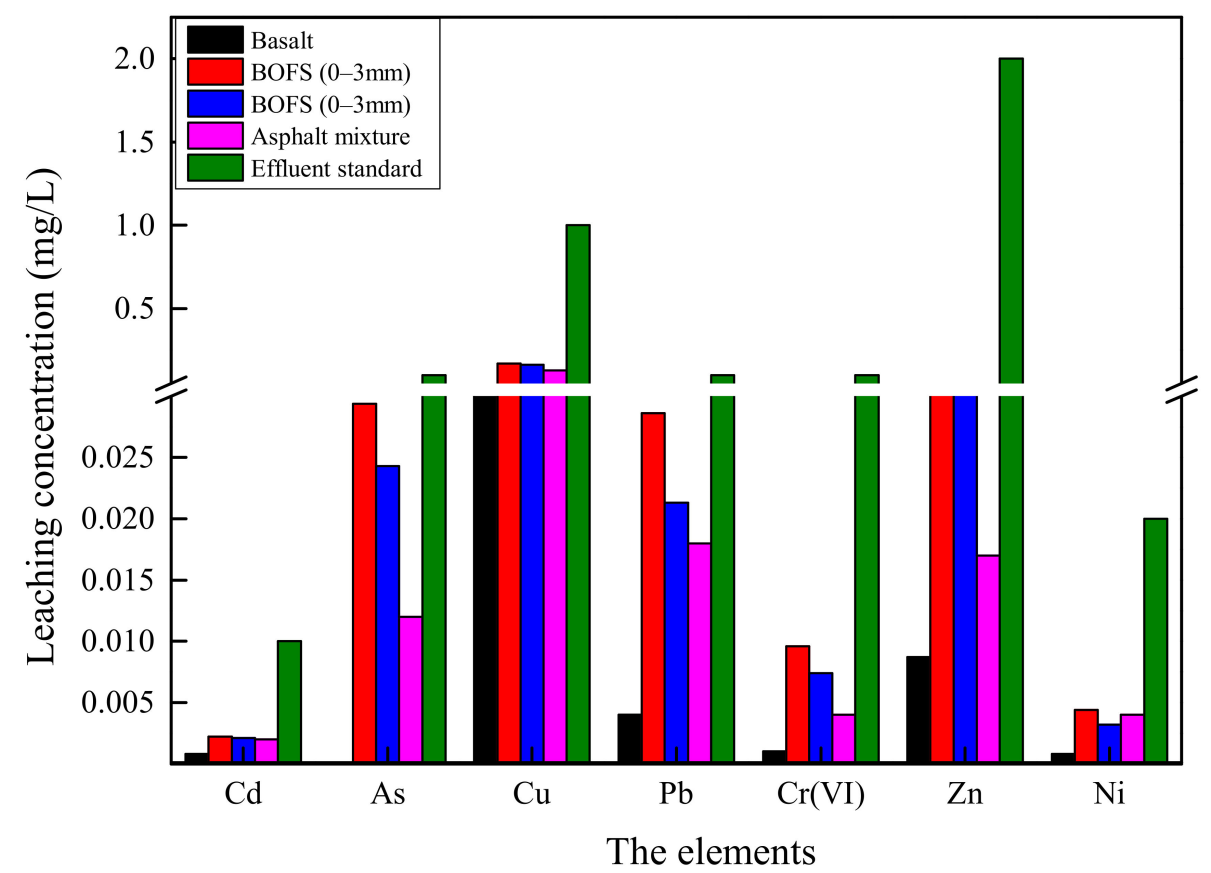

Figure 5. The leaching results of toxicity characteristic leaching procedure (TCLP) test from BOFS, basalt and asphalt mixture.

\subsubsection{Progressive TCLP Test}

The results from progressive TCLP test may give a first view of the leaching behavior of HMs from BOFS and its loose asphalt mixture (LAM). As shown in Figure 6, the concentrations of As, $\mathrm{Pb}$, 
$\mathrm{Cr}^{6+}$ and $\mathrm{Zn}$ of BOFS reached the maximum at the second cycle and $\mathrm{Cu}$ was in peak at the first cycle, then decreased along with proceeding of test in leachates. The contents of $\mathrm{Cd}$ had no remarkable difference with leaching cycles. Combined the cumulative release mass of HMs and the environmental limits, it can be found that the cumulative contents of some HMs has had an impact on environment despite the safe concentration at each extractant. The cumulative concentrations of $\mathrm{Cd}$ and $\mathrm{Ni}$ from BOFS were higher than the limits. On the basis of the results, a conclusion can be formed that BOFS can cause heavy metal pollution in long-term leaching.

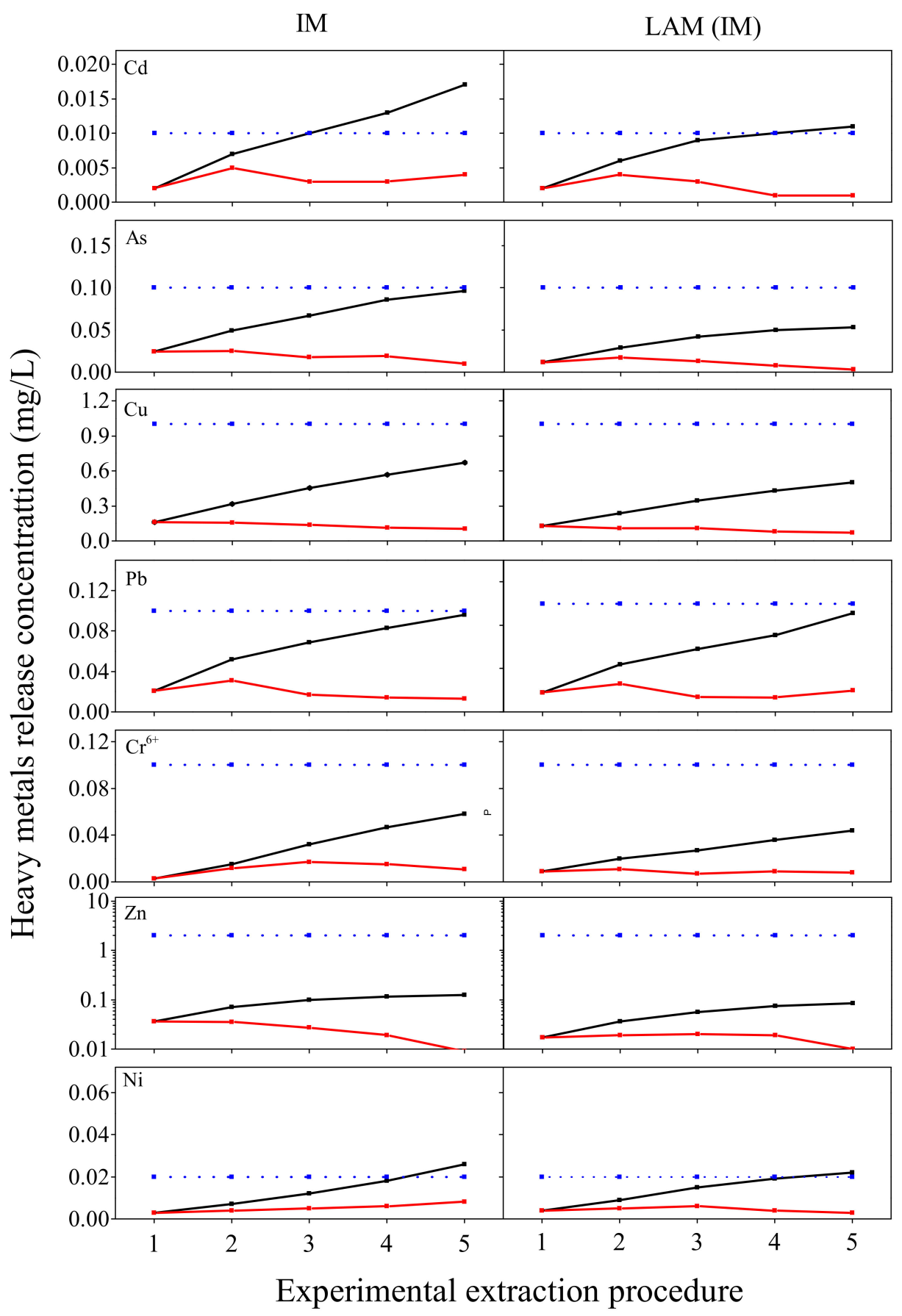

Figure 6. Release concentrations of the leaching events in progressive TCLP test; the red line represents concentration of different leaching cycles; the black line is cumulative leaching concentration and the blue line is Class IV limit of China Nations Environmental Quality Standards for surface water. 
In comparison with BOFS, the heavy metal contamination of its loose asphalt mixture is reduced remarkably. For LAM, the cumulative concentrations of $\mathrm{Cd}$ and $\mathrm{Ni}$ reached the limits, which are lower than the contamination level of BOFS. The cumulative concentration of $\mathrm{Pb}$ was satisfied with the limits, where it exceeds the limits in BOFS. It manifests that asphalt binder wrapping in the surface of BOFS can reduce effectively the HMs release and decrease the contamination level. The results correspond with J. Xue et al.'s study [40], where the leaching concentration is distinct decrease after being capsulated by asphalt in SMA mixture for BOF aggregate. But the leaching value of asphalt mixture in his research is higher, which is due to the decrease of adhesion of BOFS with asphalt in service life, resulting in the greater heavy metals release from asphalt mixture.

The leaching features of all HMs in BOFS and its asphalt mixture are presented in Figure 7. The maximum leaching content of all HMs in leachates occurred the first two times, then decreased. The essence of acid leaching is the reaction of $\mathrm{H}^{+}$ions with acid-buffer components (including mineral constituents of heavy metals) in slags [41]. At the beginning of leaching, $\mathrm{H}^{+}$ions of extractant exchanged with the toxic metals of BOFS, resulting in the release of large amounts of HMs and then the reduction of HM release with the content of HMs in BOFS decreasing. Additionally, the release concentration of all HMs in BOFS was more than that of its asphalt mixture at each cycle extraction.

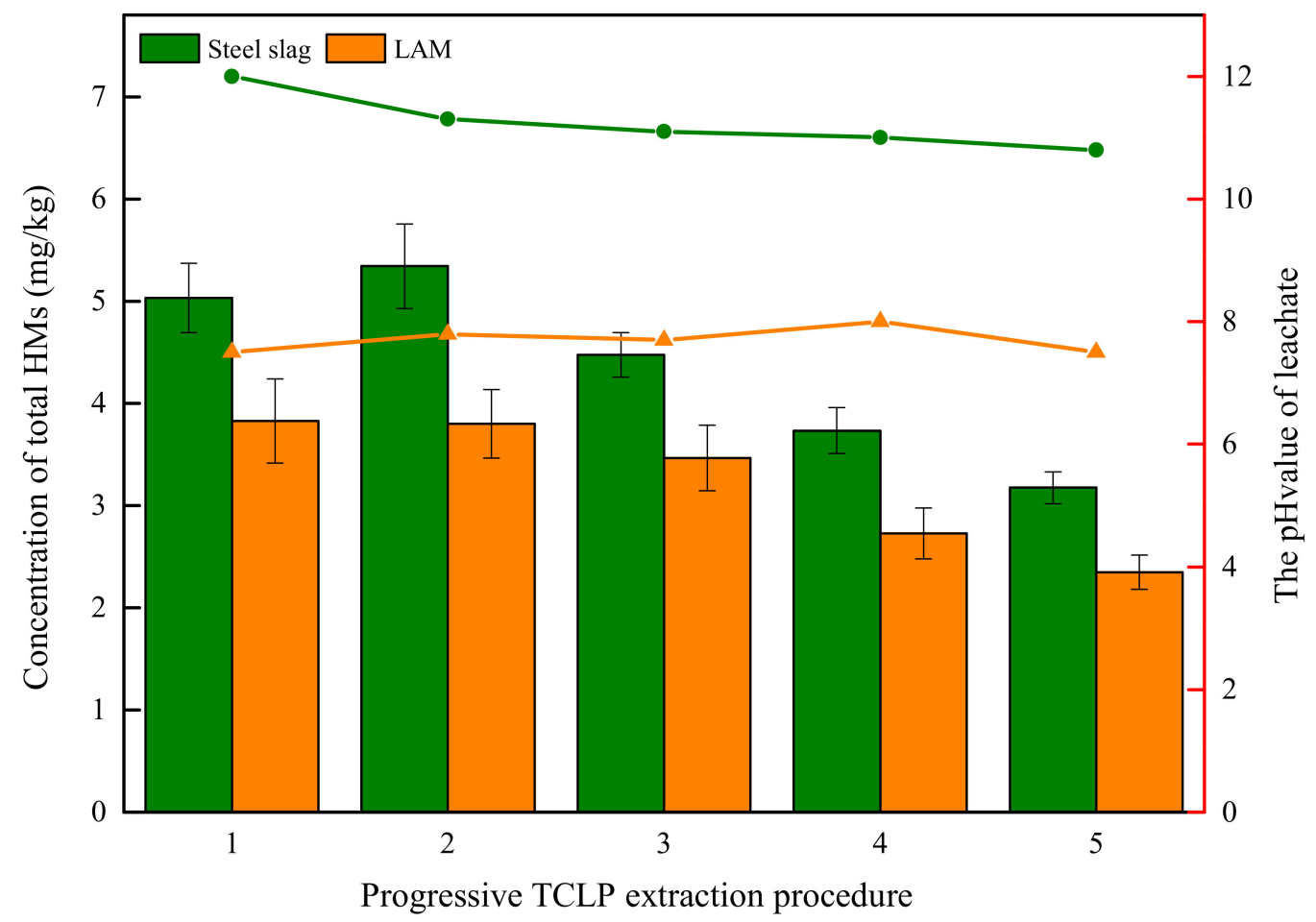

Figure 7. Concentration of all HMs and the $\mathrm{pH}$ value in progressive TCLP test.

The $\mathrm{pH}$ value of leachate has a significant positive correlation with the content of elements after the leaching events, in which higher $\mathrm{pH}$ value implies the higher content of elements in leachate. The $\mathrm{pH}$ value of BOFS leachate ranged from 10 to 12, whereas the $\mathrm{pH}$ value of LAM leachate varied from 6 to 8 . This could be due to the fact that asphalt binder has the encapsulation effect on BOFS to hinder acid-buffer components release into extractant, which contributes to the lower $\mathrm{pH}$ value after leaching events. We conclude that engineering project can decrease the contamination risk through BOFS encapsulated by asphalt binder.

\subsubsection{Cumulative Leaching Rate}

Cumulative leaching rate (r) is often used to evaluate the leaching capacity of heavy metals in solid waste. It is defined as the ratio of the cumulative release amount of metal concentrations leached 
out $\left(C_{i}\right)$ to the total metal concentrations $\left(C_{t}\right)$ in solid waste materials and can be calculated according to the following Equation (4).

$$
\mathrm{r}=\sum \frac{C_{i}}{C_{t}} \times 100 \%
$$

Cumulative leaching rate $(r)$ is considered as an important index to assess the leaching capability of HMs from BOFS and loose asphalt mixture, and quantifies the encapsulation effect of asphalt binder for HMs release, which is dependent on total concentration of HMs and leaching content from BOFS. As seen from Figure 8, the cumulative leaching rates of $\mathrm{As}, \mathrm{Cu}, \mathrm{Zn}$ and $\mathrm{Ni}$ were $8.20 \%, 19.10 \%, 1.78 \%$ and $1.59 \%$, respectively, while the $\mathrm{r}$ of $\mathrm{Cd}, \mathrm{Pb}$ and $\mathrm{Cr}^{6+}$ was less than $1 \%$ that from $\mathrm{BOFS}$.

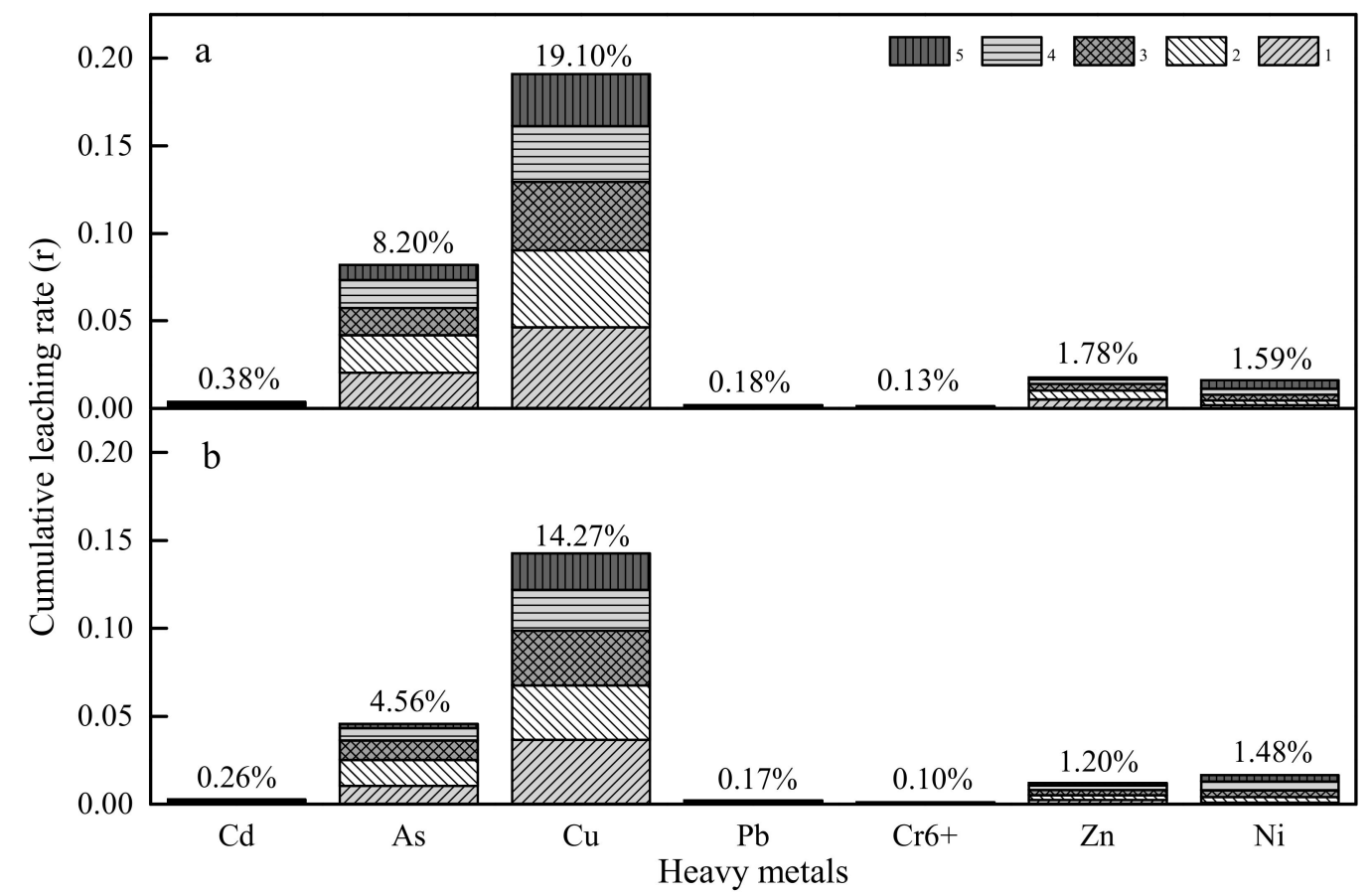

Figure 8. The cumulative leaching rate (r) (a) BOFS; (b) loose asphalt mixture (LAM).

The results from the evaluation of leaching behavior of HMs from loose asphalt mixture based on BOFS are shown in Figure 8. It is very important to mention that the amounts extracted are far less than those extracted from BOFS. Especially, the cumulative release mass of As and $\mathrm{Cu}$ from LAM reduced by $3.64 \%$ and $4.83 \%$ respectively. The leaching content of other metals did not decrease markedly due to the feebleness of the leaching capability of BOFS.

\subsection{The Release Characteristics of HMs from Asphalt Mixture}

Steel-slag-based asphalt mixture is utilized in road engineering and exhibits excellent pavement performances. R Hu et al. [42] found asphalt mixtures with BOF slag present superior moisture resistance to that with limestone and andesite. J. Xie et al. [8] found BOF slag showed superior rutting resistance with asphalt to basalt. In this chapter, we assessed asphalt mixture with BOF slag from environmental implication, where EPA method 1315 was conducted to evaluate the contamination risk of BOF-slag-based asphalt mixture as well as the mixture with asphalt stripped off (G1 and G2).

\subsubsection{The Characteristics of HMs Release from the Monolithic Sample}

Figure 9 displays the $\mathrm{pH}$ values and the elements' release for the asphalt mixture samples in the 1315 method test. As seen from Figure 9a, the pH values of G1 began at a pH of 6.2 (day 1.04) and ended at a $\mathrm{pH}$ of 7.5 (day 63), while the $\mathrm{pH}$ values of $\mathrm{G} 2$ began at a $\mathrm{pH}$ of 9.7 and ended at a $\mathrm{pH}$ of 8.5. The $\mathrm{pH}$ values of the leachate reached the maximum at day 28 and day 7 , respectively 7.2 (G1) 
and 10.5 (G2). The encapsulation effect of asphalt on BOFS hampers the acid-buffer components and HMs release, which results in low $\mathrm{pH}$ of leachate in $\mathrm{G} 1$ and prolongs the release time. Additionally, the leaching potential of HMs release from asphalt mixture increase after asphalt stripping off. As shown in Figure $9 \mathrm{~b}-\mathrm{d}$, the cumulative release mass of HMs in G2 exceeded that in G1, among which $\mathrm{Cu}$ and $\mathrm{Ni}$ were more than $100 \%$, followed by $\mathrm{Cd}$, As and $\mathrm{Cr}^{6+}$ over $50 \%$, and $\mathrm{Pb}$ was lowest, around $30 \%$.
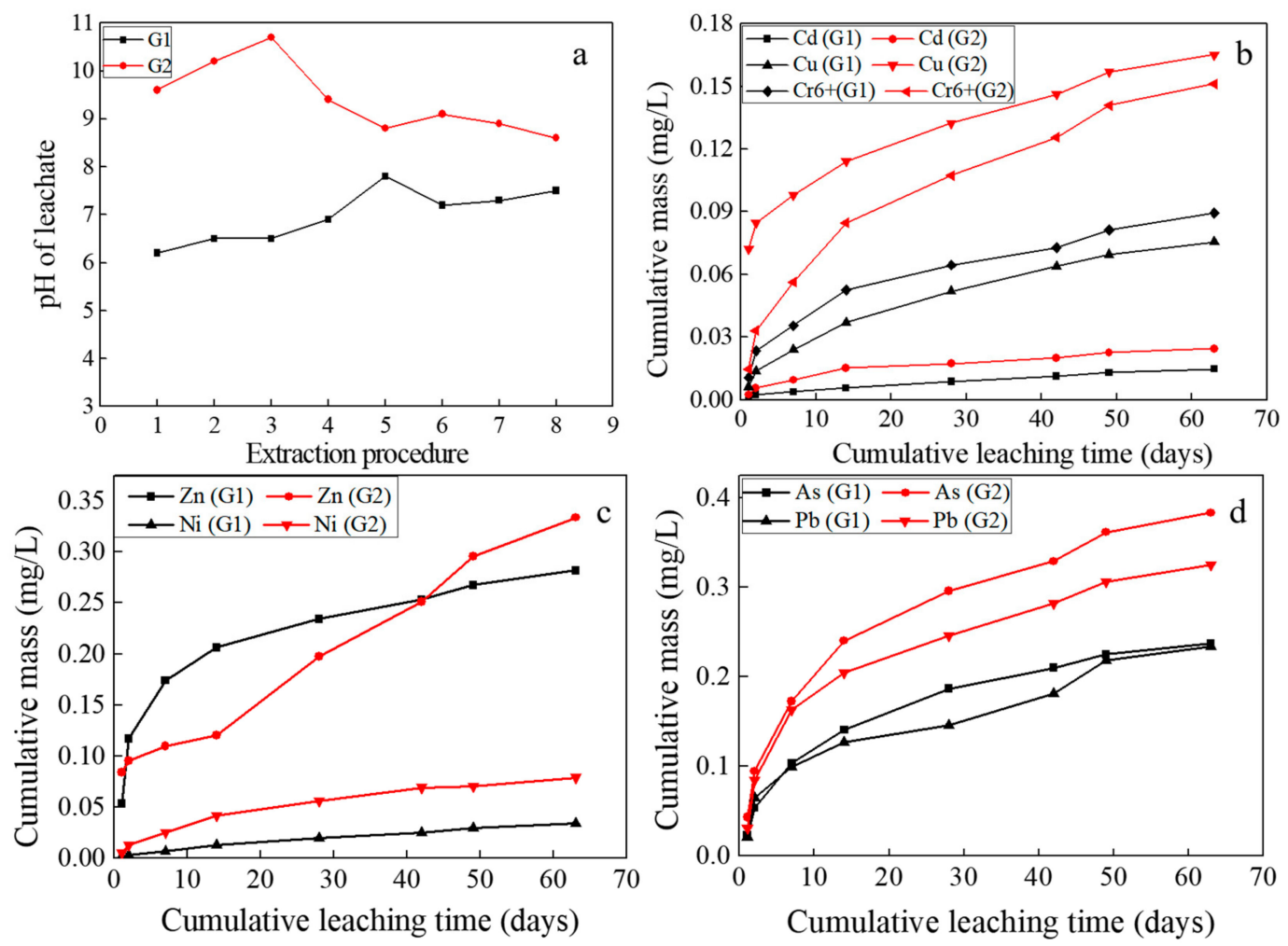

Figure 9. Evolution of $\mathrm{pH}$ and $\mathrm{HMs}$ from the monolithic asphalt mixture and that with asphalt stripped off (G1 and G2). (a) The $\mathrm{pH}$ value of the leachate, (b) The cumulative mass of $\mathrm{Cd}, \mathrm{Cu}$ and $\mathrm{Cr}^{6+}$ in the both samples, (c) The cumulative mass of $\mathrm{Zn}$ and $\mathrm{Ni}$ in the both samples, (d) The cumulative mass of $\mathrm{As}$ and $\mathrm{Pb}$ in the both samples.

\subsubsection{The Mechanisms of HMs Released from the Monolithic Sample}

To determine the release mechanisms of different elements, an approach that a graph of the cumulative mass release $\left(M_{i}\right)$ and the cumulative leaching time on a log-log scale was employed. The slope of the line was used as an indicator to assess the leaching mechanism of different metals in asphalt mixture. For diffusion to be indicated as the governing release mechanism, the slope of the line needs to fall between 0.35 and 0.65 . A slope of greater than 0.65 indicates dissolution, while depletion is defined as the predominant form of release for a slope less than $0.35[20,37]$.

Table 4 presents the slope and relevancy $\left(R^{2}\right)$ of lines of the log-log comparison of the cumulative release mass $\left(M_{i}\right)$ and the cumulative leaching time $(\mathrm{t})$. The $\mathrm{R}^{2}$ values of all fitting lines were greater than 0.94 , which shows a good fit of the regression to the measured data points. For G1, the slopes of $\mathrm{Cd}, \mathrm{As}, \mathrm{Cu}, \mathrm{Pb}$ and $\mathrm{Cr}^{6+}$ distribute between 0.35 and 0.65 , which are indicated as diffusion-controlled mechanisms, while the slope of $\mathrm{Zn}$ is less than 0.35 , deemed as depletion, and the slope of $\mathrm{Ni}$ is more than 0.65 , considered as dissolution. For G2, the release mechanism of $\mathrm{Cd}, \mathrm{As}, \mathrm{Pb} \mathrm{Cr}^{6+}$ and $\mathrm{Ni}$ are indicated as diffusion-controlled, and $\mathrm{Cu}$ and $\mathrm{Zn}$ are found to be depletion-controlled. The above results indicate that diffusion-controlled is the main release mechanism for HMs from asphalt mixtures, which also can be confirmed in other studies $[43,44]$, and the release mechanism of heavy metal could change after stripping off asphalt from BOFS. 
Table 4. Release mechanism of HMs from G1 and G2.

\begin{tabular}{ccccc}
\hline \multirow{2}{*}{ Elements } & \multicolumn{2}{c}{ G1 } & \multicolumn{3}{c}{ G2 } \\
\cline { 2 - 5 } & Slope & $\mathbf{R}^{\mathbf{2}}$ & Slope & $\mathbf{R}^{\mathbf{2}}$ \\
\hline $\mathrm{Cd}$ & 0.527 & 0.979 & 0.51 & 0.952 \\
$\mathrm{As}$ & 0.528 & 0.967 & 0.489 & 0.947 \\
$\mathrm{Cu}$ & 0.583 & 0.988 & 0.195 & 0.982 \\
$\mathrm{~Pb}$ & 0.512 & 0.972 & 0.503 & 0.948 \\
$\mathrm{Cr6}+$ & 0.472 & 0.97 & 0.524 & 0.964 \\
$\mathrm{Zn}$ & 0.346 & 0.987 & 0.331 & 0.952 \\
$\mathrm{Ni}$ & 0.744 & 0.996 & 0.611 & 0.967 \\
\hline
\end{tabular}

3.3.3. Observed Diffusivity (D ${ }^{\text {obs }}$ ) and Leachability Index (LI)

Mean diffusivity and leaching index are used to assess the mobility of heavy metal from asphalt mixture, where the results are summarized in Table 5. The $\mathrm{D}^{\text {obs }}$ values of HMs from G1 varied from $2.28 \times 10^{-7}$ to $2.09 \times 10^{-11}\left(\mathrm{~cm}^{2} / \mathrm{s}\right)$. When classified using the LI, these values fell between 6.6 and 10.7, while the $\mathrm{D}^{\text {obs }}$ values of HMs from G2 ranged from $3.78 \times 10^{-6}$ to $3.27 \times 10^{-12}\left(\mathrm{~cm}^{2} / \mathrm{s}\right)$. When classified using the LI, these values fell between 5.4 and 11.5. The LI of HMs from G1 are more than 8, described as low mobility, except As $(6.5<\mathrm{LI}<8)$ known as moderate mobility. For $\mathrm{G} 2$, the $\mathrm{LI}$ of $\mathrm{Cu}, \mathrm{Pb}, \mathrm{Cr}^{6+}$, $\mathrm{Zn}$ and $\mathrm{Ni}$ are higher than 8 , defined as low mobility, while $\mathrm{Cd}(\mathrm{LI}=7.1)$ is considered as moderate mobility and As $(\mathrm{LI}=5.4)$ is regarded as high mobility. Based on the results, we conclude that most elements of BOFS were immobilized in the monolith, with low mobility and controlled utilization, but the mobility and pollution potential could augment after stripping off asphalt.

Table 5. Observed diffusivity and leachability index of HMs.

\begin{tabular}{|c|c|c|c|c|}
\hline \multirow{2}{*}{ Elements } & \multicolumn{2}{|c|}{ G1 } & \multicolumn{2}{|c|}{ G2 } \\
\hline & $\mathrm{D}^{\mathrm{obs}}\left(\mathrm{cm}^{2} / \mathrm{s}\right)$ & LI & $\mathrm{D}^{\mathrm{obs}}\left(\mathrm{cm}^{2} / \mathrm{s}\right)$ & LI \\
\hline $\mathrm{Cd}$ & $5.01 \times 10^{-11}$ & 10.3 & $8.64 \times 10^{-8}$ & 7.1 \\
\hline As & $2.28 \times 10^{-7}$ & 6.6 & $3.78 \times 10^{-6}$ & 5.4 \\
\hline $\mathrm{Cu}$ & $2.23 \times 10^{-9}$ & 8.7 & $3.27 \times 10^{-12}$ & 11.5 \\
\hline $\mathrm{Pb}$ & $8.14 \times 10^{-11}$ & 10.1 & $5.11 \times 10^{-11}$ & 10.3 \\
\hline $\mathrm{Cr}^{6+}$ & $2.09 \times 10^{-11}$ & 10.7 & $1.07 \times 10^{-10}$ & 10 \\
\hline $\mathrm{Zn}$ & $9.57 \times 10^{-9}$ & 8.1 & $4.77 \times 10^{-10}$ & 9.3 \\
\hline $\mathrm{Ni}$ & $1.69 \times 10^{-9}$ & 8.8 & $5.71 \times 10^{-10}$ & 9.2 \\
\hline
\end{tabular}

\section{Conclusions}

The leaching behavior and contamination potential of BOFS and its asphalt mixture were determined through the evaluation of the physical-chemical features of BOFS, the TCLP test, progressive TCLP test and the monolith test. BOFS has substantial amounts of HMs, while it is a high-porosity and complicated phase constituent material. The TCLP test result showed that it has no environmental issues in short-term leaching, but it can cause heavy metal pollution in long-term leaching, which could reflect the fact that the cumulative release mass of $\mathrm{Cd}$ and $\mathrm{Ni}$ in the progressive TCLP test is more than the environmental limit. Asphalt binder can mitigate heavy metal release from BOFS by forming a matrix monolith. From the leaching rate, asphalt binder lessened the leaching amount of As and $\mathrm{Cu}$ in BOFS by $4 \%-5 \%$, while other elements did not remarkably reduce due to the low leaching rate in BOFS.

From the results of method 1315, HMs in asphalt mixture with BOFS (G1) exhibit low mobility (LI $>8)$, considered as safe disposal, expect As $(6.5<\mathrm{LI}<8)$, defined as moderate mobility, but asphalt binder stripping off can increase the mobility of heavy metal. As seen from G2, the majority of elements remain to be low mobility, but As $(\mathrm{LI}=5.4)$ is regarded as high mobility and $\mathrm{Cd}(\mathrm{LI}=7.1)$ is deemed as moderate mobility. Additionally, the "diffusion controlled" is the main release mechanism for 
heavy metal in G1 and G2, except Zn from G1 and Cu and Zn from G2 which are depletion controlled. Therefore, BOFS as an aggregate in asphalt mixtures can reduce heavy metal contamination caused by direct exposure to the environment, but asphalt binder stripping off can increase the pollution potential and mobility.

Author Contributions: J.X. and R.H. conceived and designed the experiments; R.H., C.Y. and D.Y. analyzed the data; R.H. wrote and edited the paper; S.W. and R.H. revised the work critically for important intellectual content. Conceptualization, S.W.; methodology, S.W.; software, D.Y.; validation, C.Y. and D.Y.; All authors have read and agreed to the published version of the manuscript.

Funding: This work was supported by National Natural Science Foundation of China (7181101180 and 51708437), Major Science and Technology Projects of Inner Mongolia Autonomous Region (zdzx2018029) and Hebei Provincial Communication Department project (YC-201926). Finally, this study was supported by Fundamental Research Funds for the Central Universities (WUT: 2019III201GL).

Acknowledgments: We gratefully acknowledge many important contributions from the researchers of all reports cited in our paper.

Conflicts of Interest: The authors declare no conflict of interest.

\section{References}

1. Disfani, M.M.; Arulrajah, A.; Suthagaran, V.; Bo, M.W. Long-term settlement prediction for wastewater biosolids in road embankments. Resour. Conserv. Recycl. 2013, 77, 69-77. [CrossRef]

2. Tunc, E.T. Recycling of marble waste: A review based on strength of concrete containing marble waste. J. Environ. Manag. 2018, 231, 86-97. [CrossRef] [PubMed]

3. Agnieszka, W.; Wrobel, M.; Franus, W. Woszuk Application of zeolite tuffs as mineral filler in Warm Mix Asphalt. Materials 2020, 13, 19.

4. Chao, L.; Chen, Z.; Wu, S.; Bo, L.; Xie, J.; Yue, X. Effects of steel slag fillers on the rheological properties of asphalt mastic. Constr. Build. Mater. 2017, 145, 383-391.

5. Chen, Z.; Wu, S.; Pang, L.; Xie, J. Function investigation of stone mastic asphalt (SMA) mixture partly containing basic oxygen furnace (BOF) slag. J. Appl. Biomater. Funct. Mater. 2016, 14 (Suppl. S1), e68. [CrossRef] [PubMed]

6. Xue, Y.; Wu, S.; Hou, H.; Zha, J. Experimental investigation of basic oxygen furnace slag used as aggregate in asphalt mixture. J. Hazard. Mater. 2006, 138, 261-268. [CrossRef]

7. Masad, E.; Little, D.; Sukhwani, R. Sensitivity of HMA Performance to Aggregate Shape Measured Using Conventional and Image Analysis Methods. Road Mater. Pavement Des. 2004, 5, 477-498. [CrossRef]

8. Xie, J.; Chen, J.; Wu, S.; Lin, J.; Wei, W. Performance characteristics of asphalt mixture with basic oxygen furnace slag. Constr. Build. Mater. 2013, 38, 796-803. [CrossRef]

9. Airey, G.D.; Collop, A.C.; Thom, N.H. Mechanical performance of asphalt mixtures incorporating slag and glass secondary aggregates. In Proceedings of the 8th Conference on Asphalt Pavements for Southern Africa, Sun City, South Africa, 12-16 September 2004.

10. Hesami, S.; Ameri, M.; Goli, H.; Akbari, A. Laboratory investigation of moisture susceptibility of warm-mix asphalt mixtures containing steel slag aggregates. Int. J. Pavement Eng. 2015, 16, 745-759. [CrossRef]

11. Santos, R.M.; Ling, D.; Sarvaramini, A.; Guo, M.; Elsen, J.; Larachi, F. Stabilization of basic oxygen furnace slag by hot-stage carbonation treatment. Chem. Eng. J. 2012, 203, 239-250. [CrossRef]

12. Ettler, R.V.; Johan, C.Z. Mineralogy of Medieval Slags from Lead and Silver Smelting (Bohutín, Příbram District, Czech Republic): towards estimation of historical smelting conditions*. Archaeometry 2009, 51, 987-1007. [CrossRef]

13. Navarro, A.; Cardellach, E.; Mendoza, J.L.; Corbella, M.; Domènech, L.M. Metal mobilization from base-metal smelting slag dumps in Sierra Almagrera (Almería, Spain). Appl. Geochem. 2008, 23, 895-913. [CrossRef]

14. Alina, M.; Azrina, A.; Mohd Yunus, A.S.; Izuan Effendi Halmi, M.; Radyaqsa, M. Heavy metals (mercury, arsenic, cadmium, plumbum) in selected marine fish and shellfish along the Straits of Malacca. Int. Food Res. J. 2012, 19, 135-140.

15. Houben, D.; Couder, E.o.; Sonnet, P. Leachability of cadmium, lead, and zinc in a long-term spontaneously revegetated slag heap: Implications for phytostabilization. J. Soils Sediments 2013, 13, 543-554. [CrossRef] 
16. Hall, J.L. Cellular mechanisms for heavy metal detoxification and tolerance. J. Exp. Bot. 2002, 53, 1-11. [CrossRef]

17. Douay, F.; Pelfrêne, A.; Planque, J. Assessment of potential health risk for inhabitants living near a former lead smelter. Part 1: Metal concentrations in soils, agricultural crops, and homegrown vegetables. Environ. Monit. Assess. 2013, 185, 3665-3680. [CrossRef]

18. Cheng, T.J.; Ke, D.-S.; Guo, H.-R. The association between arsenic exposure from drinking water and cerebrovascular disease mortality in Taiwan. Water Res. 2010, 44, 5770-5776. [CrossRef]

19. Amanullah, M.; Ping, W.; Amjad, A.; Mukesh, K.A.; Altaf, H.L.; Quan, W.; Ronghua, L.; Zengqiang, Z. Challenges and opportunities in the phytoremediation of heavy metals contaminated soils: A review. Ecotox. Environ. Safe 2016, 126, 111-121.

20. Roessler, J.G.; Townsend, T.G.; Ferraro, C.C. Use of leaching tests to quantify trace element release from waste to energy bottom ash amended pavements. J. Hazard. Mater. 2015, 300, 830-837. [CrossRef]

21. Huang, C.M.; Chiu, C.T.; Li, K.C.; Yang, W.F. Physical and environmental properties of asphalt mixtures containing incinerator bottom ash. J. Hazard. Mater. 2006, 137, 1742-1749. [CrossRef]

22. Ventura, A.; Monèron, P.; Jullien, A. Environmental Impact of a Binding Course Pavement Section, with Asphalt Recycled at Varying Rates. Road Mater. Pavement Des. 2008, 9 (Suppl. S1), 319-338. [CrossRef]

23. Pang, C.Q. Research on the Moisture Damage Occurred on the Asphalt Pavement. Appl. Mech. Mater. 2012, 178-181, 1117-1124. [CrossRef]

24. Yu, X.; Wang, Y.; Luo, Y.; Yin, L. The effects of salt on rheological properties of asphalt after long-term aging. Sci. World J. 2013, 2013, 921090. [CrossRef] [PubMed]

25. Kierczak, J.; Potysz, A.; Pietranik, A.; Tyszka, R.; Modelska, M.; Néel, C.; Ettler, V.; Mihaljevi, M. Environmental impact of the historical Cu smelting in the Rudawy Janowickie Mountains (south-western Poland). J. Geochem. Explor. 2013, 124, 183-194. [CrossRef]

26. Ash, C.; Borůvka, L.; Tejnecký, V.; Šebek, O.; Nikodem, A.; Drábek, O.A. Temporal dissolution of potentially toxic elements from silver smelting slag by synthetic environmental solutions. J. Environ. Manag. 2013, 129, 157-163. [CrossRef] [PubMed]

27. Moon, D.H.; Dermatas, D. An evaluation of lead leachability from stabilized/solidified soils under modified semi-dynamic leaching conditions. Eng. Geol. 2006, 85, 67-74. [CrossRef]

28. Renjith, K.R.; Sudheesh, V. Geochemical distribution, bioavailability and potential toxicity of some trace metals in a complex micro-tidal estuary, Southwest India. Toxicol. Environ. Chem. 2005, 36-52. [CrossRef]

29. Prechthai, T.; Parkpian, P.; Visvanathan, C. Assessment of heavy metal contamination and its mobilization from municipal solid waste open dumping site. J. Hazard. Mater. 2008, 156, 86-94. [CrossRef]

30. Apul, D.S.; Gardner, K.H.; Eighmy, T.T. A probabilistic source assessment framework for leaching from secondary materials in highway applications. Clean Technol. Environ. Policy 2003, 5, 120-127. [CrossRef]

31. Tiruta-Barna, L.; Imyim, A.; Barna, R. Long-term prediction of the leaching behavior of pollutants from solidified wastes. Adv. Environ. Res. 2004, 8, 697-711. [CrossRef]

32. Xue, Y.; Hou, H.; Zhu, S.; Jin, Z. Utilization of municipal solid waste incineration ash in stone mastic asphalt mixture: Pavement performance and environmental impact. Constr. Build. Mater. 2009, 23, 989-996. [CrossRef]

33. Kett, I. Marshall Method of Mix Design: Reference-ASTM Designation: D 1559. In Asphalt Materials E Mix Design Manual; Elsevier Inc.: Amsterdam, The Netherlands, 1998; pp. 102-119.

34. EPA. Test Methods for Evaluating Solid Waste, Physical/Chemical Methods. First Update, 3rd ed.; EPA: Washington, WA, USA, 1988.

35. Macdonald, D.D. The Mathematics of Diffusion. Phys. Bull. 1956, 7, 276.

36. Dermatas, D.; Moon, D.H.; Menounou, N.; Meng, X.; Hires, R.J.J. An evaluation of arsenic release from monolithic solids using a modified semi-dynamic leaching test. J. Hazard. Mater. 2004, 116, 25-38. [CrossRef]

37. Moon, D.H.; Dermatas, D.J. Arsenic and lead release from fly ash stabilized/solidified soils under modified semi-dynamic leaching conditions. J. Hazard. Mater. 2007, 141, 388-394. [CrossRef]

38. Jackson, D. Leaching of cadmium, chromium, copper, lead, and zinc from two slag dumps with different environmental exposure periods under dynamic acidic condition. Ecotoxicol. Environ. Saf. 2013, 104, 43-50.

39. Gómez-Nubla, L.; Aramendia, J.; Vallejuelo, S.F.-O.d.; Madariaga, J.M. Metallurgical residues reused as filler after 35 years and their natural weathering implications in a mountain area. Sci. Total Environ. 2018, 618, 39-47. [CrossRef] 
40. Jun, X.; Chao, Y.; Linli, Z.; Xiaojun, Z.; Shaopeng, W.; Qunshan, Y. Investigation of the Physic-Chemical Properties and Toxic Potential of Basic Oxygen Furnace Slag (BOF) in Asphalt Pavement Constructed after 15 Years. Constr. Build. Mater. 2020, 238, 117630.

41. Qing, W.; Rong-liang, Q.; Yue-na, L. Effects of simulated acid rain on cation releasing in soils of south China. Chemosphere 1998, 10, 309-315.

42. Hu, R.; Zhou, X.; Wu, S.; Yang, C.; Xie, J.; Yang, D.; Ye, Q. Bonding behavior and its affecting factors between basic oxygen furnace slag and asphalt. Constr. Build. Mater. 2020, 253, 119153. [CrossRef]

43. Dijkstra, J.J.; Sloot, H.A.V.D.; Spanka, G.; Thielen, G.A. How to Judge Release of Dangerous Substances from Construction Products to Soil and Groundwater, CPD Topic-Soil and Groundwater Impact; Report NO. ECN-C-05-045; ECN: Petten, The Netherlands, 2013.

44. Tiruta-Barna, L.R.; Barna, R.; Moszkowicz, P. Modeling of Solid/Liquid/Gas Mass Transfer for Environmental Evaluation of Cement-Based Solidified Waste. Environ. Sci. Technol. 2001, 35, 149-156. [CrossRef]

(C) 2020 by the authors. Licensee MDPI, Basel, Switzerland. This article is an open access article distributed under the terms and conditions of the Creative Commons Attribution (CC BY) license (http://creativecommons.org/licenses/by/4.0/). 